\title{
Association of sickle cell disease with nutritional status among under-five children and mediating role of hemoglobin level: secondary analysis of data from 2018 Nigeria Demographic and Health Survey
}

Mohammad Redwanul Islam

Uppsala Universitet

Md. Moinuddin

Institute of Child Health, University College London

Ayeda Ahmed

Uppsala Universitet

Syed Moshfiqur Rahman ( $\nabla$ syed.moshfiqur@kbh.uu.se)

Uppsala Universitet https://orcid.org/0000-0002-9441-0590

Research

Keywords: Sickle cell disease (SCD), Nutritional status, Anthropometric indices, Under-five children, Stunting, Hemoglobin, Mediation

Posted Date: August 17th, 2020

DOI: https://doi.org/10.21203/rs.3.rs-57486/v1

License: (c) (i) This work is licensed under a Creative Commons Attribution 4.0 International License.

Read Full License 


\section{Abstract}

Background: Malnutrition continues to affect under-five children in Africa to an overwhelming proportion. The situation is further compounded by the burden of sickle cell disease (SCD). However, association of SCD with stunting, wasting, and underweight in a nationally representative sample of under-five children remains unexplored. We aimed to describe prevalence of undernutrition by sickle cell status, to evaluate its association with growth faltering ascertained with anthropometric indices, and to explore mediating role of hemoglobin.

Methods: We availed data from the 2018 Nigeria Demographic and Health Survey (DHS) and the sample comprised 11233 children aged 6-59 months who were successfully genotyped for SCD. The DHS employed a two-stage stratified sampling strategy. SickleSCAN rapid diagnostic test was used for SCD genotyping. Z-scores of length/height-for-age (HAZ), weight-for-height (WHZ), and weight-for-age (WAZ) were computed against the 2006 World Health Organization Child Growth Standards. We fitted logistic regression models to evaluate association of SCD with stunting, wasting, and underweight. Mediation analysis was performed to capture the indirect effect of, and proportion of total effect mediated through hemoglobin level in SCD-anthropometric indices association.

Results: Prevalences of stunting, wasting, and underweight among children with SCD were 55.4\% (54.5$56.4), 9.1 \%$ (8.6-9.7), and 38.9\% (38.0-39.8), respectively. The odds of stunting were 2.39 times higher (adjusted odds ratio (aOR) 2.39, 95\% Cl: 1.26-4.54) among sickle children than those with normal hemoglobin. SCD was also significantly associated with underweight (aOR 2.64, 95\% Cl: 1.25-5.98), but not with wasting (aOR $1.60,95 \% \mathrm{Cl}: 0.85-3.02)$. Hemoglobin level significantly mediated SCD-HAZ (adjusted indirect effect (aIE) -0.328, 95\% Cl: -0.387, -0.270), SCD-WHZ (aIE - 0.080, 95\% Cl: -0.114, -0.050 ), and WAZ (alE $-0.245,95 \% \mathrm{Cl}:-0.291,-0.200$ ) associations. The extent of mediation was highest for SCD-HAZ association (adjusted proportion mediated 0.928, 95\% Cl: 0.535-2.770).

Conclusion: We presented compelling evidence of the negative impact of SCD on nutritional status of under-five children. Integration of a nutrition-oriented approach into a definitive SCD care package and its nation-wide implementation could bring promising results by mitigating the nutritional vulnerability of children with SCD.

\section{Background}

Undernutrition continues to be entrenched in Africa. An estimated 149 million under-five children were stunted globally in 2018 and 39\% of them lived in Africa. Wasting affected 49 million under-five children worldwide in 2018 and Africa was home to $28 \%$ of them. Africa is the only region that saw an escalation of the number of stunted children between 2000 and 2018 [1]. On the other hand, global burden of sickle cell disease (SCD)- the commonest inherited hemoglobinopathy- is disproportionately concentrated in sub-Saharan Africa. According to the latest Global Burden of Disease Study, incidence of SCD in 2017 exceeded 600,000 [2]. Sickle cell anemia (SCA) is the most severe variant of SCD. Sub-Saharan Africa 
hosts approximately $80 \%$ of the newborns with SCA globally. This proportion is projected to reach $88 \%$ by 2050. Nigeria accounts for $30 \%$ of the annual number of newborns with SCA, the highest country-level contribution to global tally [3]. Whereas the negative impact of SCD on children's growth is well known [4], its association with conventional anthropometric indices in a nationally representative sample of Nigerian under-five children remains unexplored.

SCD and poor nutritional status of under-five children have several critical intersections. SCD mortality among African children is high: $50 \%-90 \%$ of them reportedly die before five years of age [5]. Although lack of screening plays a role in this excessive mortality, many of the life-threatening complications of SCD among under-five children have well-recognized nutritional basis. Poor nutritional status is associated with impaired immune response to infections, and thus, drives infection-related mortality among children with SCD [4]. Nutritional status has also been implicated in the variability of SCD severity [6]. For instance, weight-for-age z-score (WAZ) has been shown to significantly predict hospitalization in SCD [7]. Therefore, nutritional status of under-five children is a promising avenue of intervention for reducing early SCD mortality and adverse prognosis [4]. Tackling undernutrition among under-five children with SCD will also contribute to overall progress toward Sustainable Development Goal Target 2.2 [8] in Nigeria- where high prevalences of growth faltering and SCD coincide. Characterization of SCD-nutritional status relationship at the national level is necessary to integrate nutritional approach to SCD management into a tailored public health package for children with SCD [9].

Children with SCD become anemic due to chronic hemolysis and low hemoglobin $(\mathrm{Hb})$ level attenuates anthropometric parameters of growth $[10,11]$. Moreover, cohort studies pinpoint $\mathrm{Hb}$ level as an independent risk factor for cerebral infarction in SCD [12]. More than one in five children with SCD suffers from overt or silent cerebral infarcts before turning 14 [13], yet stroke remains an under-recognized cause of early death among children with SCD in resource-limited settings. Accordingly, it is crucial to examine the mediating role of $\mathrm{Hb}$ level in SCD-growth faltering association. A substantial mediation will signal opportunity for dual benefit from interventions that improve $\mathrm{Hb}$ level: amelioration of growth and enhanced survival. Our objectives were to: i. describe and analyse prevalence of stunting, wasting and underweight among under-five Nigerian children by sickle cell status and socio-demographic characteristics, ii. evaluate association of SCD with growth faltering, and iii. explore $\mathrm{Hb}$ level as a mediator in SCD-growth faltering association.

\section{Methods}

\section{Study design, sampling and participants}

This cross-sectional study was based on secondary analysis of nationally representative data from the Nigeria Demographic and Health Survey 2018. It was conducted from August to December 2018 by the National Population Commission (NPC) in collaboration with the Federal Ministry of Health, along with technical assistance from The DHS Program, a United States Agency for International Development (USAID)-supported project [14]. 
A two-stage stratified sampling strategy was adopted where 37 administrative territories were split into urban and rural areas, yielding 74 sampling strata. From these strata 1400 enumeration areas (EAs) were selected. Thirty households from each EA were selected with equal-probability systematic sampling, and in a third of those 42000 households children aged 6-59 months underwent genotyping and anthropometric assessment [14]. The flow of participants into this study is illustrated in Fig. 1.

\section{Outcome variables}

The outcome variables were three common anthropometric indices of nutritional status: height-for-age, weight-for-height, and weight-for-age. These were standardized by constructing z-scores, using the World Health Organization 2006 Child Growth Standards [15]. The details of height and weight measurement can be found in the DHS final report [14]. Three forms of malnutrition were defined applying the WHOrecommended cut-offs. Stunting was defined as height-for-age z-score (HAZ) below - 2, wasting as weight-for-height z-score (WHZ) below - 2, and underweight as weight-for-age z-score (WAZ) below - 2 . For further analysis, the three outcome variables were dichotomized: stunted versus non-stunted, wasted versus non-wasted, and underweight versus non-underweight, and coded binarily ("1" versus "0").

\section{Explanatory variables}

We used data from the Biomarker Questionnaire, Household Questionnaire, and Woman's Questionnaire (DHS-7 version) to ascertain the explanatory variables selected according to existing knowledge mapped in a directed acyclic graph (DAG, Supplementary Fig. 1). The main variable of interest was sickle cell status of the children assessed with spot genotyping by SickleSCAN rapid diagnostic test kit [14]. Children with genotypes $\mathrm{HbSS}$ and $\mathrm{HbSC}$ were categorized as having SCD, those with genotypes $\mathrm{HbAS}$ and $\mathrm{HbAC}$ were categorized as "Sickle cell and $\mathrm{Hb} \mathrm{C}$ trait", and those with genotype HbAA comprised nonsickle cell children. Children's age in months was categorized into three groups $(6-23,24-40$, and 41-59 months) according to tertiles of age distribution of the sample. Wealth index was derived from data on household ownership of a range of durables and such dwelling characteristics as source of drinking water, toilet facility, and flooring material to reflect socioeconomic status (SES). It was then divided into tertiles: the highest tertile representing the richest, intermediate tertile the middle-status, and the lowest tertile the poorest households in Nigeria. According to the highest level of education attended, maternal education was categorized into none, primary, and secondary or higher. We hypothesized place of residence to reflect access to health care, as urban under-five children are likely to have greater access than their rural peers. The DHS classified EAs with a population more than 20000 as urban. Assessment of children's $\mathrm{Hb}$ level in gram per deciliter ( $\mathrm{gm} / \mathrm{dL}$ ) was performed on-site with HemoCue analyzer using capillary blood from finger/heel pricks [14]. Those with $\mathrm{Hb}<11 \mathrm{gm} / \mathrm{dL}$ were deemed anemic.

\section{Statistical analysis}


All statistical analyses accounted for the two-stage stratified sampling strategy employed in DHS with 'svyset' commands in Stata version 14.0 (Stata Statistical Software, College Station, Texas, USA). Sampling weights were applied to compensate for the unequal probability of being recruited and to obtain nationally representative estimates. Distribution of continuous, numerical data was checked by examining quantile-quantile plots. $\mathrm{HAZ}, \mathrm{WHZ}, \mathrm{WAZ}$, and $\mathrm{Hb}$ levels were approximately normally distributed. Weighted frequencies and proportions were computed for categorical data. Difference in prevalences of stunting, wasting and underweight by socio-demographic characteristics was evaluated with Chi-squared test, and difference in mean was tested with one-way ANOVA. Statistical tests were twotailed and $P$-values $<0.05$ were considered statistically significant. We fitted binary logistic regression models to explore association of SCD with stunting, wasting, and underweight. Crude and adjusted odds ratios (OR) with $95 \%$ confidence intervals $(\mathrm{Cl})$ are reported. Collinearity between categorical, explanatory variables was assessed by cross-tabulation with Chi-squared test. If found dependent $(P<0.05)$, Goodman-Kruskal's Gamma (G-K Gamma) was computed to examine the strength of association. Maternal education $(P<0.05, \mathrm{G}-\mathrm{K}$ Gamma $=0.76)$ and place of residence $(P<0.05$, G-K Gamma $=0.74)$ were strongly associated with SES, and therefore, were not included in the logistic regression. Furthermore, addition of these two variables in the adjusted model did not change effect estimates considerably $(<5 \%)$.

\section{Mediation analysis}

For mediation analysis, we included children with sickle cell and $\mathrm{Hb} \mathrm{C}$ traits (genotypes $\mathrm{HbAS}$ and $\mathrm{HbAC}$ ) and those having normal hemoglobin (genotype $\mathrm{HbAA}$ ) into one category versus children with $\mathrm{SCD}$; converting the predictor into a dichotomous one. We tested three single-mediator models [16] for SCDHAZ, SCD-WHZ, and SCD-WAZ associations with $\mathrm{Hb}$ level as a continuous, numerical mediator. Figure 2 demonstrates the outline for mediation analysis: $c$ represents the effect of SCD on the anthropometric indices after adjusting for the mediator (i.e., direct effect), and the effect of SCD on the indices through the mediator (i.e., indirect effect) is represented by $a \times b$.

We retrieved standardized total, direct, and indirect effects, and proportion of the total effects mediated, both unadjusted and after adjusting for age, sex, and SES. Standard errors and Cl were computed with bootstrapping (1000 repetitions). Mediation was assumed to occur if the indirect effect estimate, captured as average causal mediation effect (ACME), was statistically significantly different from zero. Following the recommendation by Hayes and Rockwood [17], we did not intend to identify the mediating role of $\mathrm{Hb}$ as complete or partial. A complete mediation by $\mathrm{Hb}$ level would be theoretically implausible owing to several other mechanisms that may mediate the SCD-nutritional status association [4], and we did not have data on those potential mediators. The mediated proportion was reported considering its public health relevance. Mediation analysis was also conducted in Stata.

\section{Ethics statement}


The Nigeria DHS protocol was approved by the National Health Research Ethics Committee of Nigeria (NHREC) and the ICF Institutional Review Board. Enumerators obtained informed verbal consent prior to administering the questionnaires. Blood samples were collected from the children after acquiring consent from parents/guardians [14]. We obtained approval for accessing and using the data from The DHS Program.

\section{Results}

Sample characterisitcs are presented in Table 1. The weighted analytic sample comprised 11420 children aged 6-59 months and one-third of them were younger than 24 months. The mean age of the sample was 32.2 months (standard deviation $(S D)=15.6$ ). Slightly more than half of the children were male (51\%). Genotypes HbSS and HbSC were detected among $1.3 \%$ of the children. The majority of the households were relatively affluent (the Richest, $36.8 \%$ ) and rural (56\%). Nearly $46 \%$ of the children had mothers with secondary or higher education.

\section{Prevalences of stunting, wasting, and underweight by sickle cell status and socio-demographic characteristics}

Overall prevalences of stunting, wasting, and underweight were $38.8 \%(37.9-39.7), 6.8 \%(6.3-7.2)$, and $22.2 \%$ (21.4-23.0), respectively. The prevalence of stunting increased from $33.4 \%$ among children younger than 24 months to a peak of $45.4 \%$ among children aged $24-40$ months. Contrarily, the prevalence of wasting was highest among children below 24 months of age and declined thereafter. More than one in five children younger than 24 months were underweight. Prevalences of all three forms of malnutrition were higher among the male children. The highest sex difference of 5.6 percentage points was observed for stunting prevalence: $41.5 \%$ among male versus $35.9 \%$ among female children. Children with SCD had the highest prevalences of stunting (55.4\%) and underweight (38.9\%). 
Table 1

Socio-demographic characteristics and weighted prevalences of stunting, wasting and underweight by categories of socio-demographic variables and anemia (unweighted $\mathrm{n} \approx 11233$ and weighted $\mathrm{n} \approx$

$11420)^{a}$.

$\begin{array}{ll}\text { Characteristics } & \begin{array}{l}\text { Weighted } \\ \text { frequency }^{\mathrm{b}}(\%)\end{array}\end{array}$

Stunting

prevalence

$(95 \% \mathrm{Cl})$
Wasting
prevalence

$(95 \% \mathrm{Cl})$

\section{Underweight prevalence}

$(95 \% \mathrm{Cl})$

Age (in months):

6-23

3916 (34.3)

33.4 (32.5-

34.3)

11.9 (11.3-

12.5)

$24-40$

3625 (31.7)

45.4 (44.5-

46.3)

$4.4(4.0-4.8)$

$23.3(22.5-24.1)$

41-59

3879 (34.0)

38.0 (37.1-

38.9)

$P<0.001$

$P<0.001$

$P=0.017$

Sex:

Male

$5827(51.0)$

41.5 (40.6-

42.4)

Female

5561 (49.0)

35.9 (35.0-

36.8)

$P<0.001$

$P<0.001$

$P<0.001$

Sickle cell status:

Non-sickle cell

8829 (77.3)

38.2 (37.3-

39.1)

$6.6(6.1-7.1) \quad 21.8(21.0-22.6)$

$(\mathrm{HbAA})$

Sickle cell and $\mathrm{Hb}$ C trait $\quad 2440$ (21.4)

(HbAS, AC)

Sickle cell disease

$151(1.3)$

(HbSS, SC)

$40(39.1-$

40.9)

$7.2(6.7-7.7)$

$22.9(22.1-23.7)$

$55.4(54.5-$ $56.4)$

$9.1(8.6-9.7)$

$38.9(38.0-39.8)$

$P=0.004$

$P=0.475$

$P=0.006$

Household SES:

Richest

$4197(36.8)$

$22.4(21.7-$ 23.2)

${ }^{a}$ All $P$-values derived from Chi-squared test. Missing data for variables: sex $(n=32)$, maternal education $(n=989)$, anemia $(n=27)$. ${ }^{b}$ Weighted frequencies were rounded to the nearest integer. 


\begin{tabular}{|c|c|c|c|c|}
\hline Characteristics & $\begin{array}{l}\text { Weighted } \\
\text { frequency }{ }^{b}(\%)\end{array}$ & $\begin{array}{l}\text { Stunting } \\
\text { prevalence } \\
(95 \% \mathrm{Cl})\end{array}$ & $\begin{array}{l}\text { Wasting } \\
\text { prevalence } \\
(95 \% \mathrm{Cl})\end{array}$ & $\begin{array}{l}\text { Underweight } \\
\text { prevalence } \\
(95 \% \mathrm{Cl})\end{array}$ \\
\hline Middle-status & $3589(31.4)$ & $\begin{array}{l}40.2(39.3- \\
41.1)\end{array}$ & $7.0(6.5-7.5)$ & $21.7(20.9-22.4)$ \\
\hline \multirow[t]{2}{*}{ Poorest } & $3634(31.8)$ & $\begin{array}{l}56.5(55.5- \\
57.4)\end{array}$ & $9.4(8.8-9.9)$ & $35.4(34.5-36.3)$ \\
\hline & & $P<0.001$ & $P<0.001$ & $P<0.001$ \\
\hline \multicolumn{5}{|l|}{ Place of residence: } \\
\hline Urban & $5030(44.0)$ & $\begin{array}{l}28.3(27.4- \\
29.1)\end{array}$ & $5.2(4.8-5.6)$ & $15.4(14.7-16.1)$ \\
\hline \multirow[t]{2}{*}{ Rural } & $6390(56.0)$ & $\begin{array}{l}47.1(46.2- \\
48.0)\end{array}$ & $8.0(7.5-8.5)$ & $27.7(26.8-28.5)$ \\
\hline & & $P<0.001$ & $P<0.001$ & $P<0.001$ \\
\hline \multicolumn{5}{|l|}{ Maternal education: } \\
\hline Secondary or higher & $4743(45.5)$ & $\begin{array}{l}22.1(21.3- \\
22.9)\end{array}$ & $5.0(4.5-5.4)$ & $12.0(11.4-12.6)$ \\
\hline Primary & $1708(16.4)$ & $\begin{array}{l}40.7(39.8- \\
41.7)\end{array}$ & $5.6(5.2-6.0)$ & $19.5(18.7-20.3)$ \\
\hline \multirow[t]{2}{*}{ No education } & $3980(38.1)$ & $\begin{array}{l}57.1(56.2- \\
58.1)\end{array}$ & $\begin{array}{l}9.5(8.9- \\
10.0)\end{array}$ & $35.2(34.3-36.1)$ \\
\hline & & $P<0.001$ & $P<0.001$ & $P<0.001$ \\
\hline \multirow{2}{*}{$\begin{array}{l}\text { Anemic children } \\
(\mathrm{Hb}<11 \mathrm{gm} / \mathrm{dL}) \text { : }\end{array}$} & $7736(67.9)$ & $\begin{array}{l}42.7(41.8- \\
43.7)\end{array}$ & $7.9(7.4-8.4)$ & $25.6(24.8-26.4)$ \\
\hline & & $P<0.001$ & $P<0.001$ & $P<0.001$ \\
\hline
\end{tabular}

There was an ascending gradient of prevalence of all three forms of malnutrition from non-sickle cell $(\mathrm{HbAA})$ children to those with SCD. Stunting was approximately 1.5 times more prevalent among children with SCD than their non-sickle cell peers (55.4\% versus $38.2 \%)$. Underweight was roughly 1.8 times more prevalent among children with SCD compared with non-sickle cell children (38.9\% versus $21.8 \%)$. The difference in wasting prevalence was statistically non-significant.

A socioeconomic gradient of ascending prevalence from more to less affluent households was also observed for all three forms of malnutrition. The prevalence of stunting among children from the poorest 
households was more than 2.5 times higher than that among children from the richest households ( $56.5 \%$ and $22.4 \%$, respectively). Nearly one in 10 children from the poorest households were wasted. The prevalence of underweight was 23.9 percentage points higher among children from the poorest households than those from the richest households (35.4\% versus $11.4 \%$ ). Whereas $47.1 \%$ of rural children were stunted, $28.3 \%$ of their urban peers had stunting. Children of mothers with no education had a substantially higher prevalence of stunting $(57.1 \%)$ than children born to mothers with higher educational attainment (22.1\%-40.7\%). Wasting was more prevalent among children with uneducated mothers $(9.5 \%)$ than children whose mothers had secondary education or above (5\%). While the prevalence of underweight among children of mothers with secondary education or above was $12 \%$, it rose to $35.2 \%$ among children with uneducated mothers. Approximately $43 \%$ of the anemic children were stunted and more than one in four anemic children were underweight. The prevalence of wasting among anemic children was $7.9 \%$ (Table 1 ).

\section{Mean HAZ, WHZ, and WAZ, and mean Hb level by sickle cell status}

There was significant difference in all three mean z-scores when categorized by sickle cell status and children with SCD had the lowest means. Mean HAZ among children with SCD was 36.5\% lower than non-sickle cell children (-2.17 versus - 1.59). Mean WAZ was 1.4 times lower among children with SCD in comparison to non-sickle cell children (-1.63 versus -1.13$)$. While mean $\mathrm{Hb}$ level among children with SCD was more than $2 \mathrm{gm} / \mathrm{dL}$ below than that of non-sickle cell children $(8.04 \mathrm{gm} / \mathrm{dL}$ versus

$10.19 \mathrm{gm} / \mathrm{dL})$, mean $\mathrm{Hb}$ level of children with sickle cell trait was close to that of the latter $(10.14 \mathrm{gm} / \mathrm{dL})$.

Table 2

Weighted mean HAZ, WHZ and WAZ scores, and weighted mean $\mathrm{Hb}$ level by sickle cell status among under-five children.

\begin{tabular}{|c|c|c|c|c|}
\hline Parameters & $\begin{array}{l}\text { Non-sickle } \\
\text { cell }\end{array}$ & $\begin{array}{l}\text { Sickle cell and } \mathrm{Hb} \mathrm{C} \\
\text { traits }\end{array}$ & $\begin{array}{l}\text { Sickle cell } \\
\text { disease }\end{array}$ & $\begin{array}{l}\boldsymbol{P} \\
\text { value* }\end{array}$ \\
\hline Mean HAZ score ${ }^{a}(S D)$ & $-1.59(1.57)$ & $-1.63(1.58)$ & $-2.17(1.47)$ & $<0.001$ \\
\hline Mean WHZ score ${ }^{b}(S D)$ & $-0.30(1.12)$ & $-0.36(1.13)$ & $-0.52(1.12)$ & $<0.001$ \\
\hline Mean WAZ score ${ }^{c}(S D)$ & $-1.13(1.24)$ & $-1.19(1.23)$ & $-1.63(1.16)$ & $<0.001$ \\
\hline $\begin{array}{l}\text { Mean Hb level in gm/dL } \\
\text { (SD) }\end{array}$ & $10.19(1.56)$ & $10.14(1.40)$ & $8.04(1.65)$ & $<0.001$ \\
\hline
\end{tabular}

\section{Association of SCD with stunting, wasting, and underweight}


Table 3 demonstrates the results from multiple logistic regression analyses. When adjusted for age, sex, and SES; SCD was significantly associated with stunting and underweight, but not with wasting. The odds of stunting were 2.39 times higher among children with SCD when compared with non-sickle cell children (adjusted OR (aOR) 2.39, 95\% Cl: 1.26-4.54). The odds of underweight were more than 2.5 times higher among children with SCD than their non-sickle cell peers (aOR 2.64, 95\% Cl: 1.25-5.98).

Magnitude of these associations increased in the adjusted model from the unadjusted one. Sickle cell and $\mathrm{Hb} \mathrm{C}$ trait was not associated with stunting, wasting or underweight. 
Table 3

Logistic regression models analyzing association of SCD and socio-demographic variables with stunting, wasting and underweight.

\begin{tabular}{|c|c|c|c|c|c|c|}
\hline & \multicolumn{2}{|c|}{$\begin{array}{l}\text { Stunting } \\
(H A Z<-2 S D)\end{array}$} & \multicolumn{2}{|c|}{$\begin{array}{l}\text { Wasting } \\
(\text { WHZ }<-2 \text { SD })\end{array}$} & \multicolumn{2}{|c|}{$\begin{array}{l}\text { Underweight } \\
\text { (WAZ <-2 SD) }\end{array}$} \\
\hline & $\begin{array}{l}\text { Unadjusted } \\
\text { OR (95\% } \\
\text { Cl) }\end{array}$ & $\begin{array}{l}\text { Adjusted } \\
\text { OR (95\% } \\
\text { CI) }\end{array}$ & $\begin{array}{l}\text { Unadjusted } \\
\text { OR }(95 \% \\
\mathrm{Cl})\end{array}$ & $\begin{array}{l}\text { Adjusted } \\
\text { OR (95\% } \\
\text { Cl) }\end{array}$ & $\begin{array}{l}\text { Unadjusted } \\
\text { OR }(95 \% \\
\mathrm{Cl})\end{array}$ & $\begin{array}{l}\text { Adjusted } \\
\mathrm{OR}(95 \% \\
\mathrm{Cl})\end{array}$ \\
\hline \multicolumn{7}{|l|}{ Sickle cell status: } \\
\hline $\begin{array}{l}\text { Non-sickle cell } \\
(\mathrm{Hb} A \mathrm{~A})\end{array}$ & 1 & 1 & 1 & 1 & 1 & 1 \\
\hline $\begin{array}{l}\text { Sickle cell and } \mathrm{Hb} \\
\mathrm{C} \text { traits (Hb AS, } \\
\mathrm{AC})\end{array}$ & $\begin{array}{l}1.09 \\
(0.97- \\
1.20)\end{array}$ & $\begin{array}{l}1.07 \\
(0.98- \\
1.25)\end{array}$ & $\begin{array}{l}1.01 \\
(0.86- \\
1.42)\end{array}$ & $\begin{array}{l}1.09 \\
(0.85- \\
1.41)\end{array}$ & $\begin{array}{l}1.06 \\
(0.94- \\
1.21)\end{array}$ & $\begin{array}{l}1.07 \\
(0.94- \\
1.23)\end{array}$ \\
\hline $\begin{array}{l}\text { Sickle cell disease } \\
\text { (Hb SS, SC) }\end{array}$ & $\begin{array}{l}2.02 \\
(1.24- \\
3.27)\end{array}$ & $\begin{array}{l}2.39 \\
(1.26- \\
4.54)\end{array}$ & $\begin{array}{l}1.43 \\
(0.74- \\
2.76)\end{array}$ & $\begin{array}{l}1.60 \\
(0.85- \\
3.02)\end{array}$ & $\begin{array}{l}2.28 \\
(1.26- \\
4.14)\end{array}$ & $\begin{array}{l}2.64 \\
(1.25- \\
5.98)\end{array}$ \\
\hline \multicolumn{7}{|l|}{ Age (in months): } \\
\hline $6-23$ & 1 & 1 & 1 & 1 & 1 & 1 \\
\hline $24-40$ & $\begin{array}{l}1.66 \\
(1.48- \\
1.86)\end{array}$ & $\begin{array}{l}1.74 \\
(1.53- \\
1.98)\end{array}$ & $\begin{array}{l}0.34 \\
(0.27- \\
0.43)\end{array}$ & $\begin{array}{l}0.34 \\
(0.27- \\
0.43)\end{array}$ & $\begin{array}{l}1.02 \\
(0.90- \\
1.16)\end{array}$ & $\begin{array}{l}1.01 \\
(0.88- \\
1.16)\end{array}$ \\
\hline $41-59$ & $\begin{array}{l}1.22 \\
(1.10- \\
1.37)\end{array}$ & $\begin{array}{l}1.26 \\
(1.12- \\
1.41)\end{array}$ & $\begin{array}{l}0.29 \\
(0.23- \\
0.36)\end{array}$ & $\begin{array}{l}0.28 \\
(0.22- \\
0.36)\end{array}$ & $\begin{array}{l}0.86 \\
(0.76- \\
0.97)\end{array}$ & $\begin{array}{l}0.86 \\
(0.76- \\
0.97)\end{array}$ \\
\hline \multicolumn{7}{|l|}{ Sex: } \\
\hline Male & 1 & & 1 & 1 & 1 & 1 \\
\hline Female & $\begin{array}{l}0.79 \\
(0.72- \\
0.86)\end{array}$ & $\begin{array}{l}0.76 \\
(0.70- \\
0.83)\end{array}$ & $\begin{array}{l}0.64 \\
(0.54- \\
0.79)\end{array}$ & $\begin{array}{l}0.65 \\
(0.55- \\
0.78)\end{array}$ & $\begin{array}{l}0.84 \\
(0.76-83)\end{array}$ & $\begin{array}{l}0.83 \\
(0.75- \\
0.92)\end{array}$ \\
\hline \multicolumn{7}{|l|}{ SES: } \\
\hline Richest & 1 & 1 & 1 & 1 & 1 & 1 \\
\hline Middle-status & $\begin{array}{l}2.32 \\
(1.99- \\
2.71)\end{array}$ & $\begin{array}{l}2.36 \\
(1.31- \\
1.84)\end{array}$ & $\begin{array}{l}1.68 \\
(1.26- \\
2.22)\end{array}$ & $\begin{array}{l}1.71 \\
(1.29- \\
2.26)\end{array}$ & $\begin{array}{l}2.14 \\
(1.75- \\
2.60)\end{array}$ & $\begin{array}{l}2.16 \\
(1.79- \\
2.61)\end{array}$ \\
\hline Poorest & $\begin{array}{l}4.48 \\
(3.85- \\
5.22)\end{array}$ & $\begin{array}{l}4.60 \\
(3.95- \\
5.36)\end{array}$ & $\begin{array}{l}2.30 \\
(1.77- \\
2.97)\end{array}$ & $\begin{array}{l}2.38 \\
(1.84- \\
3.07)\end{array}$ & $\begin{array}{l}4.23 \\
(3.50- \\
5.12)\end{array}$ & $\begin{array}{l}4.28 \\
(3.57- \\
5.13)\end{array}$ \\
\hline
\end{tabular}


In comparison to those younger than 24 months, the odds of stunting were $74 \%$ higher among children aged 24-40 months (aOR 1.74, 95\% Cl: 1.53-1.98). The odds of wasting were $72 \%$ lower (aOR $0.28,95 \%$ Cl: $0.22-0.36$ ) and that of underweight $14 \%$ (aOR $0.86,95 \% \mathrm{Cl}: 0.76-0.97)$ lower among those aged $41-$ 59 months. Female sex was associated with lower odds of stunting (aOR $0.76,95 \% \mathrm{Cl}: 0.70-0.83$ ), wasting (aOR 0.65, 95\% Cl: 0.55-0.78), and underweight (aOR 0.83, 95\% Cl: $0.75-0.92)$. SES showed an inverse association with the three forms of malnutrition. Children from the poorest households had more than fourfold higher odds of stunting compared with those from the richest households (aOR 4.60, 95\% Cl: 3.95-5.36).

\section{Mediating role of $\mathrm{Hb}$ level}

In the unadjusted analyses, we found all three SCD-anthropometric indices associations to be significantly mediated through $\mathrm{Hb}$ level. The statistically significant, negative indirect effects of $\mathrm{Hb}$ level became further pronounced in the adjusted analyses for all three associations. The adjusted average causal mediation effect (ACME) ranged from - 0.328 (95\% Cl: $-0.387,-0.270)$ for SCD-HAZ association to -0.080 (95\% Cl: $-0.114,-0.050)$ for SCD-WHZ association. The proportion of total effect mediated through $\mathrm{Hb}$ level was highest for SCD-HAZ association (adjusted proportion mediated 0.928; 95\% Cl: 0.535, 2.770), implying that nearly $93 \%$ of the negative effect of SCD on HAZ was mediated through lowering of $\mathrm{Hb}$ level. 
Table 4

Unweighted mediation analyses of $\mathrm{Hb}$ level as a mediator in the SCD-anthropometric indices association $(n=11048)$.

SCD-HAZ score association

\begin{tabular}{|c|c|c|c|c|}
\hline & $\begin{array}{l}\text { Unadjusted } \\
\text { estimate }\end{array}$ & $95 \% \mathrm{Cl}$ & $\begin{array}{l}\text { Adjusted } \\
\text { estimate }\end{array}$ & $95 \% \mathrm{Cl}$ \\
\hline $\begin{array}{l}\text { Indirect effect } \\
\left(\mathrm{ACME}^{\mathrm{a}}\right)\end{array}$ & $-0.444 * *$ & $\begin{array}{l}-0.515 \\
-0.380\end{array}$ & $-0.328 * *$ & $\begin{array}{l}-0.387 \\
-0.270\end{array}$ \\
\hline Proportion mediated & $1.358 *$ & $0.726,4.800$ & $0.928 * *$ & $0.535,2.770$ \\
\hline \multicolumn{5}{|c|}{ SCD-WHZ score association } \\
\hline Indirect effect (ACME) & $-0.134 \star \star$ & $\begin{array}{l}-0.171 \\
-0.100\end{array}$ & $-0.080 * \star$ & $\begin{array}{l}-0.114 \\
-0.050\end{array}$ \\
\hline Proportion mediated & $0.609 *$ & $0.299,2.900$ & $0.373^{\star}$ & $0.158,2.010$ \\
\hline \multicolumn{5}{|c|}{ SCD-WAZ score association } \\
\hline Indirect effect (ACME) & $-0.342^{\star \star}$ & $\begin{array}{l}-0.397 \\
-0.290\end{array}$ & $-0.245^{\star \star}$ & $\begin{array}{l}-0.291 \\
-0.200\end{array}$ \\
\hline Proportion mediated & $0.982 \star \star$ & $0.637,2.190$ & $0.664 * \star$ & $0.423,1.320$ \\
\hline
\end{tabular}

\section{Discussion}

We found significant variation in prevalences of stunting and underweight by sickle cell status, and these were markedly high among children with SCD. Prevalences varied significantly by socio-demographic characteristics as well. Stunting prevalence exceeded $50 \%$ among children from the poorest households. Mean z-scores of all three anthropometric indices were notably lower among children with SCD. Regression analyses revealed significant association of SCD with stunting and underweight. Hb level emerged as a statistically significant mediator in the association of SCD with all three anthropometric indices. The extent of mediation by $\mathrm{Hb}$ level was markedly high for SCD-HAZ association. To the best of our knowledge, this is one of the first analyses of association of SCD with nutritional status accounting for biological and socioeconomic correlates in a nationally representative sample.

The negative impact of SCD on anthropometric measures of nutritional status has been persistently captured in studies from Nigeria [18] and elsewhere [7, 19-24]. Proposed mechanisms fall into three broad categories: elevated resting energy expenditure (REE), reduced dietary intake, and metabolic and endocrine alterations $[4,25,26]$. A combination of increased protein turnover due to accelerated erythropoiesis and increased cardiac workload secondary to anemia and consequent hypoxia results in a higher REE among children with SCD [4]. Dietary intake is postulated to reduce from appetite suppression by high blood level of inflammatory mediators, particularly interleukin-6 [4], and during episodes of acute 
complications and hospitalization [27]. Dietary intake that is nutritionally adequate for children without SCD is unlikely to be sufficient for children with the condition because of the increased REE [4]. This may have driven growth faltering disproportionately among under-five children with SCD in Nigeria, where children's dietary and feeding practices remain suboptimal and compounded by poverty and food insecurity $[28,29]$. The extent to which suboptimal diet may amplify the impact of SCD on nutritional status in sub-Saharan Africa needs to be explored in future.

The magnitude of SCD's association with stunting and underweight in our analyses was high with OR surpassing two. As the 2018 Nigeria DHS is the first DHS to implement SCD genotyping in a nationally representative sample [14], we could not find nation-wide studies to compare the effect sizes with. In their prospective study involving a hospital-based cohort $(n=1618)$ in Tanzania, Cox et al. reported OR for stunting and underweight of 1.82 (95\% Cl: 1.43-2.32) and 2.61 (95\% Cl: 2.06-3.31), respectively, at enrolment. The mean age of the cohort was 10.1 years (range $0.5-48$ years) [7]. Considering the older age distribution of participants, the lower OR for stunting versus our analyses (1.82 vs. 2.39) may reflect a survivor cohort effect [30]. The OR for stunting and underweight among children under 12 years of age were 4.87 (95\% Cl: 2.94-8.06) and 4.74 (95\% Cl: 2.96-7.60), respectively, in a cross-sectional study from the Democratic Republic of the Congo (DRC; $n=455)$ [21]. The higher OR compared to our analyses could be a manifestation of difference in HbS gene haplotype [31]; as Bantu haplotype predominates in DRC, whereas Benin haplotype is pre-eminent in Nigeria [32].

Interestingly, we did not find a statistically significant association between SCD and wasting. This contradicts some of the previous studies [7, 23]. Pooled analyses show that the trajectory of mean WHZ in the first five years of life is different from that of mean HAZ and WAZ. Faltering in WHZ is concentrated between 3-15 months of age, and thereafter, it recovers steadily [33]. We posit that wasting could be an adaptive response to redirect energy and nutrients for maintaining essential metabolic processes [7], and it begins to accelerate as children with SCD live beyond the first five years. Of note, both studies $[7,23]$ finding significant SCD-wasting association had higher age distribution of participants with smaller number in the under-five category. Alternatively, the SCD-wasting non-association in this study may be a reflection of phenotypic difference owing to distinct HbS haplotypes [31].

The mean HAZ, WHZ, and WAZ of children with SCD in this study were significantly lower than their peers with HbAA genotype. The most severe deficit was observed for mean HAZ of children with SCD (-2.17, SD 1.47). This is appreciably lower than mean HAZ from children with SCD in llesa, Nigeria (- 0.52, SD 1.33) [18]; Enugu, Nigeria (- 0.50, SD 1.57) [34]; Ghana (- 0.86, SD 1.40) [35]; and Kenya (-1·10, SD 1·00) [36]. However, in the Kenyan SCD cohort $(n=128)$ with median age of 21.1 months, mean HAZ and WAZ did not significantly differ from those of non-sickle cell children [36]. No significant difference in mean HAZ was reported also in the study from Enugu, Nigeria [34] that recruited outpatient cases and controls from a tertiary hospital $(n=116)$. The mean age of cases in that study was 40.6 months (SD 16.79). The mean WAZ of -1.63 (SD 1.16) among children with SCD found in our study is suggestive of a drastic left shift in weight-for-age trajectory compared with the WHO Child Growth Standards. An unitary increase in WAZ reduces hospitalization risk among children with SCD by $13 \%$ [7]. Besides, mortality risk for sickle children 
with WAZ below - 3 can be threefold higher (adjusted hazard ratio 3.42; 95\% $\mathrm{Cl}$ : 2.50-4.68) [37]. The low mean WAZ in our study, therefore, signals increased likelihood of adverse prognosis for communitydwelling Nigerian children with SCD lacking definitive care. Moreover, the better anthropometric indices recorded among facility-recruited children with SCD indicates that early diagnosis and access to care can minimize growth faltering to a large extent.

The mean $\mathrm{Hb}$ level of sickle children in our study $(8.04 \mathrm{gm} / \mathrm{dL}, \mathrm{SD} 1.65)$ was similar to that found in a multi-country (Mali, Senegal, Cameroon, Gabon, and the Ivory Coast) analysis [38], and in studies from Ghana [35] and Brazil [23]; but higher than that of Kenyan cohorts [36, 39]. We captured a significant mediating role of $\mathrm{Hb}$ in SCD-nutritional status association. While this is unsurprising as chronic hemolytic anemia lies at the core of pathophysiologic alterations in SCD [31], the extent of mediation has enormous public health implication. Robust studies show $\mathrm{Hb}$ concentration to positively correlate with z-scores of height, weight, and BMI as well as growth velocity in $\operatorname{SCD}[10,20]$. Our mediation analysis corroborates this by pinpointing the extent of SCD's impact on conventional anthropometric indices mediated through $\mathrm{Hb}$ level. Approximately $93 \%$ of the impact on $\mathrm{HAZ}, 37 \%$ of that on $\mathrm{WHZ}$, and $66 \%$ of that on $\mathrm{WAZ}$ was mediated through $\mathrm{Hb}$ level. Hence, improved $\mathrm{Hb}$ level could prevent deterioration of nutritional status to a large extent. Furthermore, low $\mathrm{Hb}$ is a consistent predictor of stroke and mortality among children with $\operatorname{SCD}[12,40]$. This mediation analysis, therefore, highlights the critical need for interventions to optimize $\mathrm{Hb}$ level among under-five children with SCD; including universal point-of-care screening in early infancy, hydroxyurea therapy, and judicious use of blood transfusion [9]. The pitfalls of blood transfusion in African settings concern unavailability of transfusable blood, transmission of infections, and alloimmunization. Local trials are needed to guide context-appropriate use of blood transfusion for underfive children with SCD in Nigeria and to examine its impact on nutritional status and mortality [40].

Some limitations of this study must be acknowledged for allowing careful interpretation of the findings. Because of the cross-sectional design, causal inferences cannot be drawn. Nevertheless, it is noteworthy that although clinical presentation takes time to fully develop, the genetic changes underlying SCD are present at birth. The rapid diagnostic test (SickleSCAN) used for SCD genotyping in the DHS showed diagnostic sensitivity and specificity of $85 \%$ and $98 \%$, respectively, when compared with highperformance liquid chromatography [14]. We did not have data on energy intake, blood nutrient levels and $\mathrm{HbF}$ concentration, which could have made the analysis comprehensive. We adjusted for age, sex, and SES in the statistical model, but residual confounding could not be ruled out. Generalizability of the results to other countries in sub-Saharan Africa could be limited by phenotypic variation in SCD and difference in socio-demographic attributes.

\section{Conclusion}

We presented compelling evidence of the association of SCD with stunting and underweight among under-five children in a setting burdened with childhood undernutrition and an under-five mortality rate of 132 per 1000 live births [14]. Mediation analysis indicated that measures to improve $\mathrm{Hb}$ level of Nigerian children with SCD may safeguard against growth faltering and enhance survival. Deteriorating nutritional 
status poses considerable threat to well-being of children with SCD and render them prone to adverse prognosis. Integration of a nutrition-oriented approach into a definitive SCD care package [9] and its implementation at scale is needed to mitigate nutritional vulnerability of these children.

\section{Abbreviations}

SCD: Sickle Cell Disease; DHS: Demographic and Health Survey; HAZ: Height-for-Age Z-score; WHZ: Weight-for-Height Z-score; WAZ: Weight-for-age Z-score; aOR: Adjusted Odds Ratio; aIE: Adjusted Indirect Effect; Hb: Hemoglobin; NPC: National Population Commission, Nigeria; USAID: United States Agency for International Development; EA: Enumeration Area; DAG: Directed Acyclic Graph; SES: Socio-Economic Status; Cl: Confidence Interval; G-K Gamma: Goodman-Kruskal's Gamma; ACME: Average Causal Mediation Effect; NHREC: National Health Research Ethics Committee, Nigeria; ICF: Inner City Fund; SD: Standard Deviation; REE: Resting Energy Expenditure; DRC: The Democratic Republic of The Congo; HbF: Hemoglobin F (Fetal Hemoglobin).

\section{Declarations}

\section{Ethics approval and consent to participate}

The Nigeria DHS protocol was approved by the National Health Research Ethics Committee of Nigeria (NHREC) and the ICF Institutional Review Board. Respondents were asked to provide verbal informed consent after full disclosure of the purpose and voluntary nature of participation.

\section{Consent for publication}

Consent to use and publish articles emanating from this dataset was obtained along with the dataset from the Demographic and Health Survey (DHS)

\section{Availability of data materials}

Datasets are available upon request from The DHS Program website:

https://dhsprogram.com/data/dataset/Nigeria_Standard-DHS_2018.cfm?flag=0. The datasets analyzed during the current study are available on reasonable request.

\section{Competing interests}

The authors declare no competing interests.

\section{Funding}


The authors received no specific grant from any funding agency in public, commercial or not-for-profit sectors.

\section{Authors' Contributions}

MRI conceived the idea, conceptualized and contributed to study design, planning the analysis and manuscript writing. SMR and AA extracted the datasets and performed data management. AA reviewed the manuscript. MMU and SMR performed the analysis, and reviewed the manuscript critically. MMU guided the analysis with statistical insights. SMR supervised the entire work. All authors reviewed and approved the final manuscript.

\section{Acknowledgements}

Not applicable

\section{References}

1. United Nations Children's Fund (UNICEF), World Health Organization, World Bank Group. Levels and trends in child malnutrition: key findings of the 2019 Edition of the Joint Child Malnutrition Estimates [Internet]. Geneva: WHO; 2019 Mar. Available from: https://www.who.int/nutgrowthdb/estimates2018/en/.

2. James SL, Abate D, Abate KH, Abay SM, Abbafati C, Abbasi N, et al. Global, regional, and national incidence, prevalence, and years lived with disability for 354 diseases and injuries for 195 countries and territories, 1990-2017: a systematic analysis for the Global Burden of Disease Study 2017. The Lancet. 2018;392:1789-858.

3. Piel FB, Hay SI, Gupta S, Weatherall DJ, Williams TN. Global Burden of Sickle Cell Anaemia in Children under Five, 2010-2050: Modelling Based on Demographics, Excess Mortality, and Interventions. Osrin D, editor. PLoS Med. 2013;10:e1001484.

4. Hyacinth HI, Adekeye OA, Yilgwan CS. Malnutrition in Sickle Cell Anemia: Implications for Infection, Growth, and Maturation. J Soc Behav Health Sci. 2013;7.

5. Grosse SD, Odame I, Atrash HK, Amendah DD, Piel FB, Williams TN. Sickle Cell Disease in Africa. Am J Prev Med. 2011;41:398-405.

6. Umeakunne K, Hibbert JM. Nutrition in sickle cell disease: recent insights. NDS. 2019;Volume 11:917.

7. Cox SE, Makani J, Fulford AJ, Komba AN, Soka D, Williams TN, et al. Nutritional status, hospitalization and mortality among patients with sickle cell anemia in Tanzania. Haematologica. 2011;96:948-53. 
8. United Nations. Sustainable Development Goal 2 [Internet]. Sustainable Development Goals Knowledge Platform. 2020 [cited 2020 Jun 28]. Available from: https://sustainabledevelopment.un.org/sdg2.

9. Oron AP, Chao DL, Ezeanolue EE, Ezenwa LN, Piel FB, Ojogun OT, et al. Caring for Africa's sickle cell children: will we rise to the challenge? BMC Med. 2020;18:92.

10. Wolf RB, Saville BR, Roberts DO, Fissell RB, Kassim AA, Airewele G, et al. Factors associated with growth and blood pressure patterns in children with sickle cell anemia: Silent Cerebral Infarct MultiCenter Clinical Trial cohort: Growth and BP in SCA. Am J Hematol. 2015;90:2-7.

11. Singhal A, Morris J, Thomas P, Dover G, Higgs D, Serjeant G. Factors affecting prepubertal growth in homozygous sickle cell disease. Arch Dis Child. 1996;74:502-6.

12. Ohene-Frempong K, Weiner SJ, Sleeper LA, Miller ST, Embury S, Moohr JW, et al. Cerebrovascular accidents in sickle cell disease: rates and risk factors. Blood. 1998;91:288-94.

13. DeBaun MR, Derdeyn CP, McKinstry RC. Etiology of strokes in children with sickle cell anemia. Ment Retard Dev Disabil Res Rev. 2006;12:192-9.

14. National Population Commission (NPC), ICF. Nigeria Demographic and Health Survey 2018 [Internet]. Abuja, Nigeria, and Rockville. Maryland: NPC and ICF; 2019. p. 707. Report No.: 6. Available from: dhsprogram.com.

15. WHO Multicentre Growth Reference Study Group. WHO Child Growth Standards based on length/height, weight and age. Acta Paediatr. 2006;95:76-85.

16. O'Laughlin KD, Martin MJ, Ferrer E. Cross-Sectional Analysis of Longitudinal Mediation Processes. Multivar Behav Res. 2018;53:375-402.

17. Hayes AF, Rockwood NJ. Regression-based statistical mediation and moderation analysis in clinical research: Observations, recommendations, and implementation. Behav Res Ther. 2017;98:39-57.

18. Adegoke SA, Figueiredo MS, Adekile AD, Braga JAP. Comparative study of the growth and nutritional status of Brazilian and Nigerian school-aged children with sickle cell disease. International Health. 2017;9:327-34.

19. Barden EM, Kawchak DA, Ohene-Frempong K, Stallings VA, Zemel BS. Body composition in children with sickle cell disease. The American Journal of Clinical Nutrition. 2002;76:218-25.

20. Zemel BS, Kawchak DA, Ohene-Frempong K, Schall JI, Stallings VA. Effects of Delayed Pubertal Development, Nutritional Status, and Disease Severity on Longitudinal Patterns of Growth Failure in Children With Sickle Cell Disease. Pediatr Res. 2007;61:607-13.

21. Lukusa Kazadi A, Ngiyulu RM, Gini-Ehungu JL, Mbuyi-Muamba JM, Aloni MN. Factors Associated with Growth Retardation in Children Suffering from Sickle Cell Anemia: First Report from Central Africa. Anemia. 2017;2017:1-6.

22. Al-Saqladi A-WM, Bin-Gadeen HA, Brabin BJ. Growth in children and adolescents with sickle cell disease in Yemen. Ann Trop Paediatr. 2010;30:287-98. 
23. Silva CM, Viana MB. Growth Deficits in Children with Sickle Cell Disease. Arch Med Res. 2002;33:308-12.

24. Osei TB, Apprey C, Mills-Robertson FC, Ohemeng AN. Nutritional status of children with sickle cell disease: A study at the Komfo Anokye Teaching Hospital of Ghana. Nutrition Food Science. 2019;49:232-9.

25. Borel MJ, Buchowski MS, Turner EA, Peeler BB, Goldstein RE, Flakoll PJ. Alterations in basal nutrient metabolism increase resting energy expenditure in sickle cell disease. Am J Physiol. 1998;274:E35764.

26. Mandese V, Bigi E, Bruzzi P, Palazzi G, Predieri B, Lucaccioni L, et al. Endocrine and metabolic complications in children and adolescents with Sickle Cell Disease: an Italian cohort study. BMC Pediatrics. 2019;19:56.

27. Malinauskas BM, Gropper SS, Kawchak DA, Zemel BS, Ohene-Frempong K, Stallings VA. Impact of Acute Illness on Nutritional Status of Infants and Young Children With Sickle Cell Disease. J Am Diet Assoc. 2000;100:330-4.

28. Steyn NP, Walker AR. Nutritional status and food security in Sub-Saharan Africa: Predictions for 2020. Asia Pacific Journal of Clinical Nutrition. 2000;9:1-6.

29. Olatona FA, Adenihun JO, Aderibigbe SA, Adeniyi OF. Complementary Feeding Knowledge, Practices, and Dietary Diversity among Mothers of Under-Five Children in an Urban Community in Lagos State, Nigeria. Int J MCH AIDS. 2017;6:46-59.

30. Saracci R. Survival-related biases survive well. Int J Epidemiol. 2007;36:244-6.

31. Piel FB, Steinberg MH, Rees DC. Sickle Cell Disease. Longo DL, editor. N Engl J Med. 2017;376:156173.

32. Bitoungui VJN, Pule GD, Hanchard N, Ngogang J, Wonkam A. Beta-Globin Gene Haplotypes Among Cameroonians and Review of the Global Distribution: Is There a Case for a Single Sickle Mutation Origin in Africa? OMICS. 2015;19:171-9.

33. Shrimpton R, Victora CG, de Onis M, Lima RC, Blossner M, Clugston G. Worldwide Timing of Growth Faltering: Implications for Nutritional Interventions. PEDIATRICS. 2001;107:e75-5.

34. Bismarck Eke C, Onyeka Edelu B, Nnaemeka Ikefuna A, Josephine Emodi I, Chidozie Ibe B. Obesity in Preschool-Aged Children with Sickle Cell Anemia: Emerging Nutritional Challenge in a Resource Limited Setting. Pediatr Hematol Oncol. 2015;32:390-8.

35. Boadu I, Ohemeng A, Renner LA. Dietary intakes and nutritional status of children with sickle cell disease at the Princess Marie Louise Hospital, Accra - a survey. BMC Nutr. 2018;4:33.

36. Uyoga S, Macharia AW, Mochamah G, Ndila CM, Nyutu G, Makale J, et al. The epidemiology of sickle cell disease in children recruited in infancy in Kilifi, Kenya: a prospective cohort study. The Lancet Global Health. 2019;7:e1458-66.

37. Moïsi J, Gatakaa H, Berkley J, Maitland K, Mturi N, Newton C, et al. Excess child mortality after discharge from hospital in Kilifi, Kenya: a retrospective cohort analysis. Bull World Health Org. 2011;89:725-32. 
38. Alexandre-Heymann L, Dubert M, Diallo DA, Diop S, Tolo A, Belinga S, et al. Prevalence and correlates of growth failure in young African patients with sickle cell disease. $\mathrm{Br} J$ Haematol. 2019;184:253-62.

39. Macharia AW, Mochamah G, Uyoga S, Ndila CM, Nyutu G, Makale J, et al. The clinical epidemiology of sickle cell anemia In Africa. Am J Hematol. 2018;93:363-70.

40. Makani J, Cox SE, Soka D, Komba AN, Oruo J, Mwamtemi H, et al Mortality in Sickle Cell Anemia in Africa: A Prospective Cohort Study in Tanzania. Schrijver I, editor. PLoS ONE. 2011;6:e14699.

\section{Tables}

Due to technical limitations, the tables are provided in the Supplementary Files section.

\section{Figures}




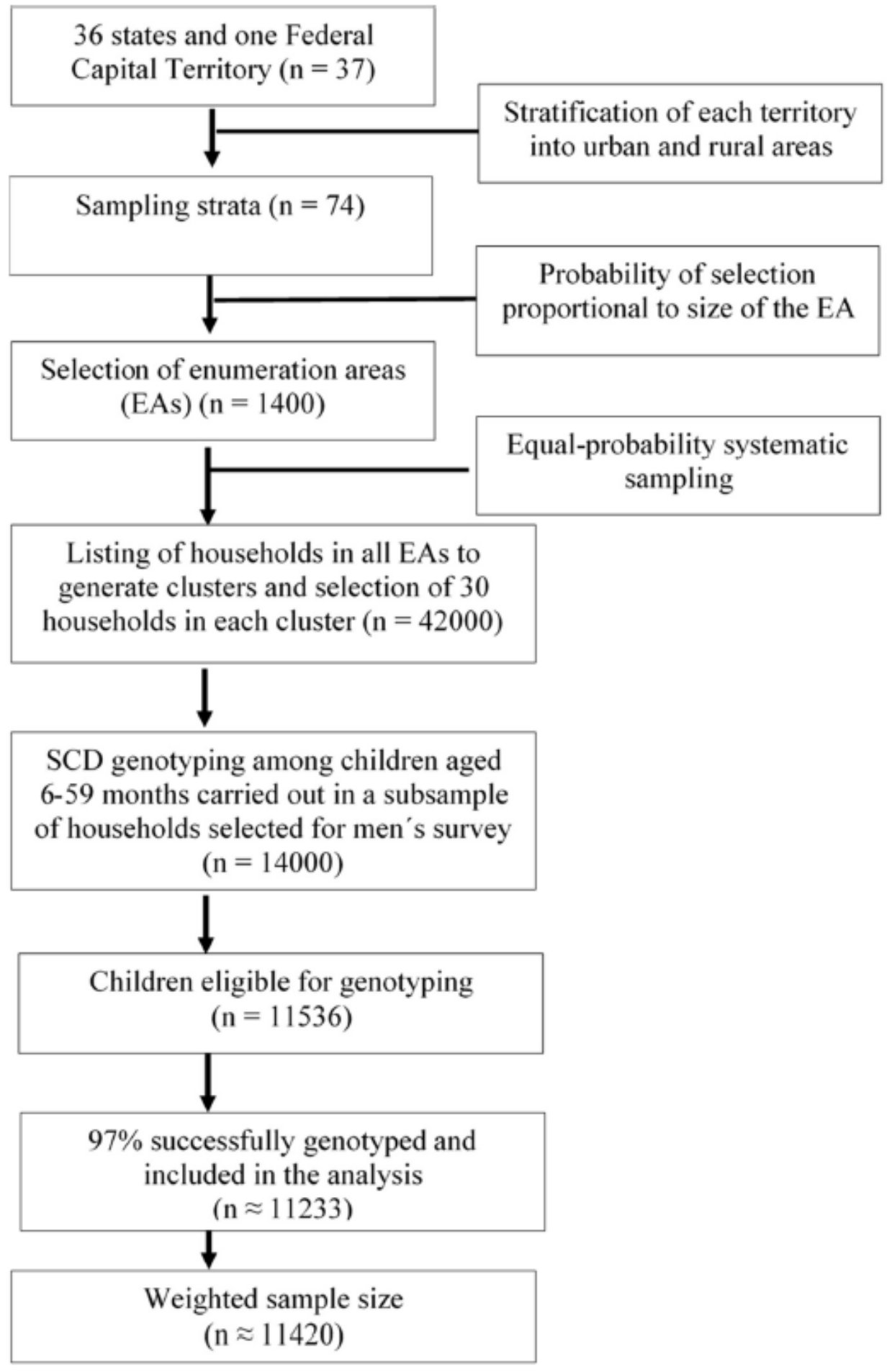

\section{Figure 1}

Flow diagram of children included in the analytic sample of this study. 


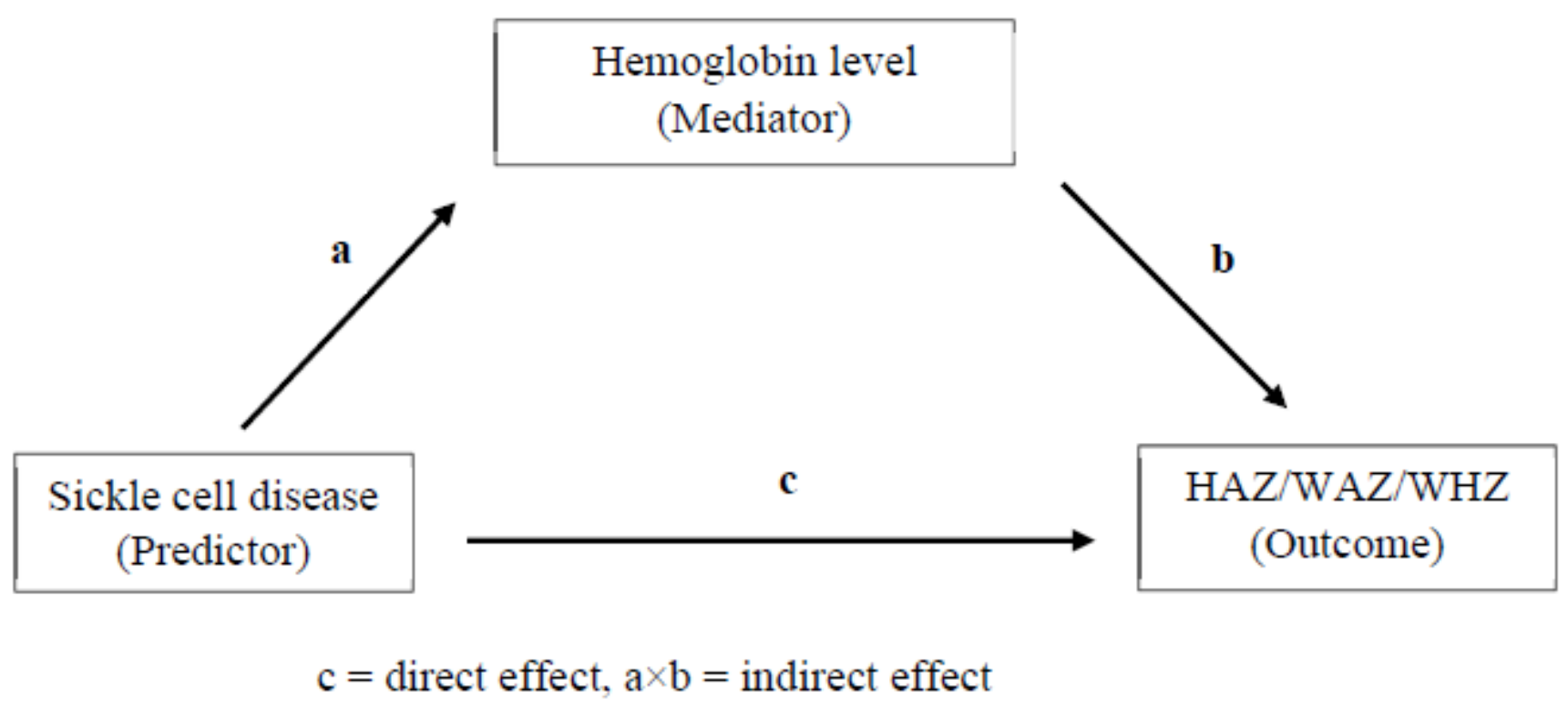

Figure 2

Path diagram showing $\mathrm{Hb}$ level as a mediator in SCD-anthropometric indices associations.

\section{Supplementary Files}

This is a list of supplementary files associated with this preprint. Click to download.

- Table1Sociodemographiccharacteristicsofthechildren.pdf

- Table1Sociodemographiccharacteristicsofthechildren.pdf

- Table2WeihgtedNSbySCD.pdf

- Table2WeihgtedNSbySCD.pdf

- Table3LogisticregressionmodelsforSCDandNS.pdf

- Table3LogisticregressionmodelsforSCDandNS.pdf

- Table4UnweihgtedmediationanalysisofHb.pdf

- Table4UnweihgtedmediationanalysisofHb.pdf

- SupplentaryFigure1DirectedAcyclicGraph.pdf

- SupplentaryFigure1DirectedAcyclicGraph.pdf

- STROBEnutchecklisttablelslametal.docx

- STROBEnutchecklisttablelslametal.docx 